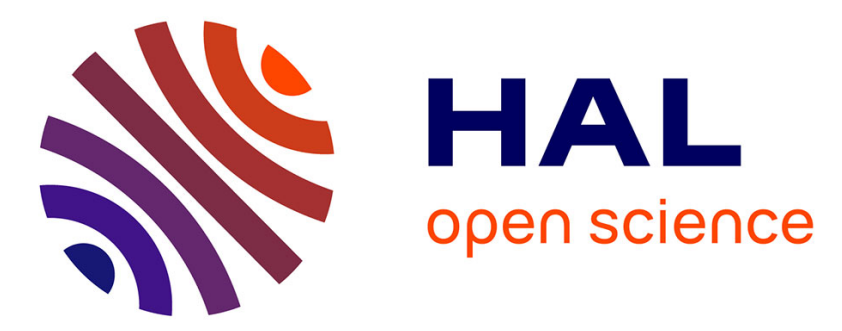

\title{
Structural Analysis and Theoretical Investigations of the Magnetocaloric Effect for La0.7Ba0.15Ag0.15MnO3 Manganite Prepared Using Sol-Gel Route
}

Sobhi Hcini, Mohamed Hsini, Hussein Al Robei, Mohamed Lamjed Bouazizi, Michel Boudard

\section{To cite this version:}

Sobhi Hcini, Mohamed Hsini, Hussein Al Robei, Mohamed Lamjed Bouazizi, Michel Boudard. Structural Analysis and Theoretical Investigations of the Magnetocaloric Effect for La0.7Ba0.15Ag0.15MnO3 Manganite Prepared Using Sol-Gel Route. Journal of Superconductivity and Novel Magnetism, 2020, 33 (11), pp.3597-3605. 10.1007/s10948-020-05615-x * hal-03127714

\section{HAL Id: hal-03127714 \\ https://hal.univ-grenoble-alpes.fr/hal-03127714}

Submitted on 11 Oct 2021

HAL is a multi-disciplinary open access archive for the deposit and dissemination of scientific research documents, whether they are published or not. The documents may come from teaching and research institutions in France or abroad, or from public or private research centers.
L'archive ouverte pluridisciplinaire HAL, est destinée au dépôt et à la diffusion de documents scientifiques de niveau recherche, publiés ou non, émanant des établissements d'enseignement et de recherche français ou étrangers, des laboratoires publics ou privés. 


\title{
Structural analysis and theoretical investigations of the magnetocaloric effect for $\mathrm{La}_{0.7} \mathrm{Ba}_{0.15} \mathrm{Ag}_{0.15} \mathrm{MnO}_{3}$ manganite prepared using sol-gel route
} Sobhi Hcini ${ }^{1, *}$, Mohamed Hsini ${ }^{2}$, Hussein Al Robei ${ }^{3}$, Mohamed Lamjed Bouazizi ${ }^{3}$, Michel Boudard ${ }^{4}$

${ }^{1}$ Research unit of valorization and optimization of exploitation of resources, Faculty of Science and Technology of Sidi Bouzid, Kairouan University, 9100 Sidi Bouzid, Tunisia.

${ }^{2}$ Laboratory of Physical Chemistry of Materials, Physics Department, Faculty of Sciences of Monastir, Monastir University, 5019 Monastir, Tunisia.

${ }^{3}$ Department of Mechanical Engineering, College of Engineering, Prince Sattam Bin Abdulaziz University, 11942 Alkharj, Saudi Arabia.

${ }^{4}$ University of Grenoble Alpes, LMGP, CNRS, 38000 Grenoble, France.

*Corresponding author: E-mail address: hcini_sobhi@yahoo.fr (S. Hcini)

\begin{abstract}
Structural analysis, magnetocaloric properties, and theoretical investigations of the magnetocaloric effect were carried out in the crystalline $\mathrm{La}_{0.7} \mathrm{Ba}_{0.15} \mathrm{Ag}_{0.15} \mathrm{MnO}_{3}$ manganite prepared using sol-gel route. The phase purity and structure of this sample were checked by X-ray diffraction technique and Rietveld analysis. From magnetic measurements, the ferromagnetic to paramagnetic (FM-PM) phase transition was observed around $T_{C}=255 \mathrm{~K}$. The maximum change in magnetic entropy $\left(\Delta S_{M}^{\max }\right)$ and relative cooling power (RCP)

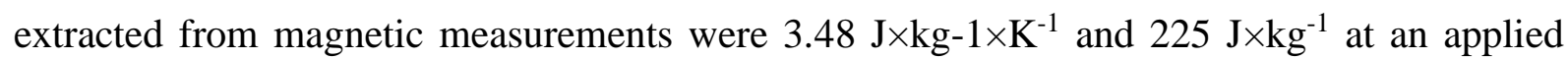
magnetic field of $5 \mathrm{~T}$. These magnetocaloric parameters offer to the sample the possible use in the magnetic refrigeration technology. The magnetic-entropy simulation by using different theories such as the Weiss molecular mean-field theory and the Landau theory shows good correlation between the theoretical values of $-\Delta S_{M}(T)$ and the experimental ones estimated from Maxwell relation.
\end{abstract}

Keywords: Manganites; Sol-gel route, Structural analysis; Magnetocaloric effect; Spontaneous magnetization, Theoretical models. 


\section{Introduction}

The magnetic refrigeration (MR) seems to be one of the very serious alternatives for replacing conventional refrigeration systems based on compression-expansion of gases [1]. This new technique, compared to the traditional techniques, has several advantages. It is more energy efficient, more compact and above all less harmful to the environment. The MR relies on the MCE (magnetocaloric effect), which is an intrinsic property of magnetic materials and results in an instantaneous and reversible variation of their temperature and entropy when they are subjected to a variation of magnetic field. This reversible effect is maximal at the FM-PM transition temperature (called the Curie temperature $T_{C}$ ), and is the consequence of the decrease in magnetic entropy following the alignment of the electronic spins under the application of the magnetic field. However, the optimization of the magnetic refrigerator devices depends on a solid thermodynamic description of the magnetic material. Different theories are developed and presented in this case. For example, the mean-field theory has established direct relations between magnetic entropy change and magnetization [2, 3]. Moreover, the theory of critical exponents justifies the existence of a universal magnetocaloric behavior in materials presenting second order magnetic phase transitions [4, 5]. The studies of critical exponents can supply valuable information about magnetic phase transitions. In addition, the Landau theory which is a mean field theory is used to the theoretical modeling of the MCE [6, 7]. The effect of the magnetoelastic coupling and electron condensation energy on the magnetic entropy change has been considered in this theory.

Among materials having good MCE, the manganites with perovskite structure adopting $\mathrm{Ln}_{1-\mathrm{x}} \mathrm{M}_{\mathrm{x}} \mathrm{MnO}_{3}$ as general formula $(\mathrm{Ln}=$ trivalent rare earth element, and $\mathrm{M}=$ monovalent or divalent ion) represent a family of materials that was widely studied years ago for MR technology due to their rich properties [8-17]. Recently, these materials have been 
widely studied due to their extremely high chemical stability over a wide range of compositions. This results in numerous modifications of their properties both on the fundamental scale and for potential applications.

In this work, we have prepared manganite sample with $\mathrm{La}_{0.7} \mathrm{Ba}_{0.15} \mathrm{Ag}_{0.15} \mathrm{MnO}_{3}$ composition using sol-gel method. This compound belongs to the family of lanthanum manganites and its silver-doped alloys, $\mathrm{La}_{1-\mathrm{x}} \mathrm{Ag}_{\mathrm{x}} \mathrm{MnO}_{3}$, a subject of considerable renewed interest in the magnetic refrigeration technology [18-20]. We have successively studied the structural, and magnetocaloric properties for the $\mathrm{La}_{0.7} \mathrm{Ba}_{0.15} \mathrm{Ag}_{0.15} \mathrm{MnO}_{3}$ sample. We have also presented theoretical investigations of the magnetic entropy change for this sample using different theories, and the results were compared with the experimental ones.

\section{Synthesis and characterizations}

For the sol-gel synthesis of $\mathrm{La}_{0.7} \mathrm{Ba}_{0.15} \mathrm{Ag}_{0.15} \mathrm{MnO}_{3}$ manganite, the nitrates were selected as $\mathrm{La}\left(\mathrm{NO}_{3}\right)_{3} \cdot 6 \mathrm{H}_{2} \mathrm{O}, \mathrm{Ba}\left(\mathrm{NO}_{3}\right)_{2}, \mathrm{AgNO}_{3}$, and $\mathrm{Mn}\left(\mathrm{NO}_{3}\right)_{3} 4 \mathrm{H}_{2} \mathrm{O}$, all with high purity. These nitrates were mixed according to the stoichiometric ratio and dissolved in distilled water with heating at $90{ }^{\circ} \mathrm{C}$, followed by the addition of citric acid and ethylene glycol. Then, amounts of ammonia have been added in order to maintain the $\mathrm{pH}$ of the solution to about 7. After some time of heating (approximately $4 \mathrm{~h}$ ), a viscous gel is observed. This gel was dried for $12 \mathrm{~h}$ at $250{ }^{\circ} \mathrm{C}$, and the resulting precursor was ground in an agate mortar. The obtained powder was undergone two cycles of (grinding $\rightarrow$ pelleting $\rightarrow$ sintering) at $600{ }^{\circ} \mathrm{C}$ and $800{ }^{\circ} \mathrm{C}$ for $24 \mathrm{~h}$, respectively. The resulting powder was sintered, in a final step, at $1000{ }^{\circ} \mathrm{C}$ for $24 \mathrm{~h}$.

The phase purity of the synthesized sample was inspected via X-ray diffraction (XRD) technique, using $\mathrm{Cu}-\mathrm{K} \alpha$ radiation $(\lambda=1.5406 \AA$ ). "Fullprof" program is used to perform the Rietveld refinement of structural parameters. "Quantum design" physical properties measurement system (PPMS) is used to measure both $M(T)$ and $M\left(\mu_{0} H, T\right)$ data: $M(T)$ curve was measured at ZFC (zero field cooling) at a weak magnetic field $\left(\mu_{0} H=0.05 \mathrm{~T}\right)$ in $150 \mathrm{~K} \leq$ 
$T \leq 350 \mathrm{~K}$ temperature range, and the $M\left(\mu_{0} H, T\right)$ isotherm measurements were taken near $T_{C}$ vs temperature in $0 \mathrm{~T} \leq \mu_{0} H \leq 5 \mathrm{~T}$ magnetic field interval.

\section{Results and discussions}

\subsection{XRD analysis}

The XRD pattern for $\mathrm{La}_{0.7} \mathrm{Ba}_{0.15} \mathrm{Ag}_{0.15} \mathrm{MnO}_{3}$ manganite is shown in Fig. 1a. The pattern shows a pure perovskite phase with no detectable secondary phases. The sample crystallized in the rhombohedral crystal structure having space group $R \overline{3} c$ and space group number 167. The observed broadening of the diffraction peaks seems consistent with nanometric crystallite size. The structural parameters were calculated from Rietveld refinement of the obtained XRD pattern (Fig. 1b), and they are represented in Table 1. The obtained cell parameters are $a=b=5.5216$ (1) $\AA, c=13.4259$ (3), $\alpha=90^{\circ}, \beta=90^{\circ}$ and $\gamma=$ $120^{\circ}$. The unit cell volume is $V=354.487$ (8) $\AA^{3}$. These lattice parameters are higher than those presented for the rhombohedral $\mathrm{La}_{0.85} \mathrm{Ag}_{0.15} \mathrm{MnO}_{3}$ in Refs. [21, 22]. Obviously the $\mathrm{Ba}$ for La substitution causes the increase of lattice parameters in $\mathrm{La}_{0.85} \mathrm{Ag}_{0.15} \mathrm{MnO}_{3}$ sample. This is in agreement with the smaller ionic radius of $\mathrm{La}\left(r_{\mathrm{La}}{ }^{3+}=1.032 \AA\right)$ compared to that for $\mathrm{Ba}$ $\left(r_{\mathrm{Ba}}{ }^{2+}=1.35 \AA\right)$ [23]. The crystallite size was calculated using the full-width at half maximum (FWHM) of the most intense peak $\left(\begin{array}{lll}1 & 1 & 0\end{array}\right)$ by Scherrer's formula [24]:

$t=\frac{0.9 \lambda}{\beta \cos (\theta)}$

where, $\beta$ is the full width at half maximum of the peak at $2 \theta, \theta$ is the corresponding Bragg angle, and $\lambda$ is the wavelength. The measured crystallite size is about $46 \mathrm{~nm}$. All the other structural parameters including site symmetry, Wyckoff positions, isotropic Debye-Waller factors, atomic positions, bond length, bond angle, and agreement factors are also presented in

\section{Table 1.}




\subsection{Magnetocaloric properties}

Fig. 2a presents the $M(T)$ curve taken at $\mu_{0} H=0.05 \mathrm{~T}$ for $\mathrm{La}_{0.7} \mathrm{Ba}_{0.15} \mathrm{Ag}_{0.15} \mathrm{MnO}_{3}$ manganite. By representing the $d M / d T$ curve (inset of Fig. 2a), the Curie temperature of the FM-PM phase transition was determined as $T_{C}=255 \mathrm{~K}$. To understand the magnetic order in the sample, the magnetization $M\left(\mu_{0} H, T\right)$ isotherms are presented in Fig. 2b. As illustrated in this figure, the $M\left(\mu_{0} H, T\right)$ isotherms gradually decrease with increasing temperature. In addition, with the increase of $\mu_{0} H$ values, the magnetization increases non-linearly in the low temperature range with a tendency to saturation reflecting a ferromagnetic behavior, and varies linearly at high $T$ values sign of paramagnetic behavior. Fig. 2c, shows the Arrott plots $\left(M^{2}\right.$ vs $\left.\mu_{0} H / M\right)$ which show positive slopes [25]. These positive slopes of $M^{2}$ vs $\mu_{0} H / M$ confirm the second-order magnetic phase-transition for $\mathrm{La}_{0.7} \mathrm{Ba}_{0.15} \mathrm{Ag}_{0.15} \mathrm{MnO}_{3}$ manganite [26]. The magnetic entropy $\left(-\Delta S_{M}\right)$ was given from $M\left(\mu_{0} H, T\right)$ data by the following Maxwell relations [1]:

$$
\begin{aligned}
& \left(\frac{\partial S}{\partial \mu_{0} H}\right)_{T}=\left(\frac{\partial M}{\partial T}\right)_{\mu_{0} H} \\
& \left(\frac{\partial S}{\partial M}\right)_{T}=-\left(\frac{\partial \mu_{0} H}{\partial T}\right)_{M}
\end{aligned}
$$

Using Eq. (2), the $-\Delta S_{M}$ values can be estimated as:

$$
\Delta S_{M}\left(T, \Delta \mu_{0} H\right)=\int_{0}^{\mu_{0} H}\left(\frac{\partial M}{\partial T}\right)_{\mu_{0} H} d \mu_{0} H
$$

The obtained $-\Delta S_{M}$ values for different applied fields are represented in Fig. 2d. As shown in this figure, the $-\Delta S_{M}(T)$ variation reaches a maximum peak near the order temperature $\left(T_{C}\right)$ as $\left|\Delta S_{M}^{\max }\right|=3.48 \mathrm{~J} \times \mathrm{kg}^{-1} \times K^{-1}$ at $\mu_{0} H=5 \mathrm{~T}$. The relative cooling power (RCP) at different applied fields is estimated by multiplying the width at half height and the maximum value of magnetic entropy change according the following relation [1]:

$R C P=\left|\Delta S_{M}^{\max }\right| \times \delta T_{F W H M}$ 
The RCP value is equal to $225 \mathrm{~J} \mathrm{~kg}^{-1}$ at $\mu_{0} H=5 \mathrm{~T}$. The RCP and $\left|\Delta S_{M}^{\max }\right|$ values at $\mu_{0} H=5 \mathrm{~T}$ for the present sample besides those of some Gd based materials [27], and other manganite samples [11-17] are compared in Table 2. We noted that the maximum entropy change for $\mathrm{La}_{0.7} \mathrm{Ba}_{0.15} \mathrm{Ag}_{0.15} \mathrm{MnO}_{3}$ sample, which is about $37 \%$ of that of pure $\mathrm{Gd}$, is larger than the $\left|\Delta S_{M}^{\max }\right|$ values reported for some manganites considered for magnetic refrigeration technology $[\mathbf{1 1}, \mathbf{1 3}, \mathbf{1 6}]$, and much smaller than the pseudo binary alloy $\mathrm{Gd}_{5} \mathrm{Si}_{2} \mathrm{Ge}_{2}[\mathbf{2 1}]$. However the sample exhibits a large relative cooling power which is about $55 \%$ of that of Gd. Consequently, the present sample can be used as an active magnetic refrigerator in a relatively wide range of temperatures nearing $255 \mathrm{~K}$ with a relatively large entropy change.

\subsection{Spontaneous magnetization}

In the ferromagnetic state (below $T_{C}$ ), each ferromagnetic material acquires a spontaneous magnetization. The $\left(-\Delta S_{M}\right)$ expression is given $v s$ the spontaneous magnetization $\left(M_{\text {spont }}\right)$ as follows $[\mathbf{2 8}, \mathbf{2 9}]$ :

$-\Delta S_{M}(\sigma)=\frac{3 J}{J+1} N k_{B}\left(\sigma^{2}+\sigma_{\text {spont }}^{2}\right)=\frac{3 J}{M_{0}(J+1)} N k_{B}\left(M^{2}+M_{\text {spont }}^{2}\right)$

where $\sigma_{\text {spont }}=\frac{M_{\text {spont }}}{M_{0}}$ is the reduced spontaneous magnetization, $J$ is the angular spin value, $N$ is the number of spins, $k_{B}$ is the Boltzmann constant, and $M_{0}$ is the saturation magnetization. To estimate the spontaneous magnetization for $\mathrm{La}_{0.7} \mathrm{Ba}_{0.15} \mathrm{Ag}_{0.15} \mathrm{MnO}_{3}$ compound, we adjusted linearly the Arrott plots $\left(\frac{\mu_{0} H}{\mathrm{M}} v s \mathrm{M}^{2}\right)$ in Fig. 3a, and the $\left(-\Delta S_{M} v s M^{2}\right)$ curves in Fig. $3 \mathbf{b}$ for $T<T_{C}$. These two figures show that all the curves obey the same regularity and have practically constant slopes in the temperature range below $T_{C}$. Fig. 3c shows a good agreement between $M_{\text {spont }}$ values obtained according to the mean field theory and those calculated from Arrott plots. The good correlation between the both methods confirms the validity of the mean field theory for estimation of the spontaneous magnetization. According to the scaling method [30], the critical exponent $(\beta)$ is associated to 
$M_{\text {spont }}$ and the reduced temperature $\varepsilon=\frac{T-T_{C}}{T_{C}}$ in the FM region $\left(T<T_{C}\right)$ by the following relation:

$M_{\text {spont }} \approx \log \left(M_{0}\right)+\beta \log (-\varepsilon)$

Using this relation, a linear adjustment of $\log \left(M_{\text {spont }}\right) v s \log (-\varepsilon)$ curve was carried out as shown in Fig. 3d. Here, we used the $M_{\text {spont }}$ values estimated from $-\Delta S_{M} v s M^{2}$ curves. The obtained $\beta$ value $(\beta=0.49)$ is close to that of the mean field model $(\beta=0.5)$. This confirms the utility of the mean field theory in the case of our system.

\subsection{Landau theory}

According to the Landau's theory, the Gibbs free energy development to order six is given by [25]:

$F(T, M) \cong F_{0}+\frac{1}{2} A(T) M^{2}+\frac{1}{4} B(T) M^{4}+\frac{1}{6} C(T) M^{6}+\cdots-M H$,

here the Landau coefficients $A(T), B(T)$, and $C(T)$ represent the magnetoelastic coupling and electrons interaction, and they are temperature-dependent parameters [31]. The examination of the free-energy expression demonstrates that the parameter $A(T)$ is always positive and would get a minimum value at the Curie temperature corresponding to a maximum of the susceptibility. On the other hand, the order of the magnetic transition is governed by the sign of $B(T)$ at the transition: a first-order transition takes place if $B(T)<0$ while a second order occurs when $B(T) \geq 0$ [32]. Besides, $C(T)$ is positive at $T_{C}$ but in other cases, it is negative or positive. By adjusting the Arrott curves (Fig. 4a), the three Landau coefficients are determined using the equation of the state given at the equilibrium condition $\left(\frac{d F(T, M)}{d M}=0\right)$ :

$\frac{\mu_{0} H}{M}=A(T)+B(T) M^{4}+C(T) M^{6}$.

Figs. 4(b-d) show the variations of $A, B$, and $C$ coefficients $v s T$. From Fig. 4c, it is clear that $B(T)$ is positive at $T_{C}$ confirming the second-order nature of the FM-PM transition. By deriving $A, B$ and $C v s T$, the $-\Delta S_{M}(T)$ can be estimated as follows: 
$-\Delta S_{M}(T)=\frac{1}{2} A^{\prime} M^{2}+\frac{1}{4} B^{\prime} M^{4}+\frac{1}{6} C^{\prime} M^{6}$

where $A^{\prime}=\frac{\partial A}{\partial T}, B^{\prime}=\frac{\partial B}{\partial T}$ and $C^{\prime}=\frac{\partial C}{\partial T}$. Fig. 5 shows a good agreement between $-\Delta S_{M}(T)$ curves obtained on the basis of Landau theory (red lines) and the experimental ones calculated using the Maxwell relation. Our results estimated by Landau theory, by pushing the development of the Gibbs function to order six, correlate better with the experimental ones than in the case of some other manganites [33-36] where the development of the Gibbs free energy was limited to order four.

\subsection{Mean-field approach}

The magnetization $(M)$, for a ferromagnetic material, can be adjusted according to the Brillouin function $B_{J}(x)$ as [37]:

$M=f\left(\frac{\mu_{0} H+H_{\text {exch }}}{T}\right)=M_{0} B_{J}(x)$

where $T$ is the temperature, $\mu_{0} H$ is the applied magnetic field, $H_{\text {exch }}=\lambda M$ is the exchange field ( $\lambda$ is the mean-field exchange parameter), and $B_{J}(x)$ function can be expressed as:

$B_{J}(x)=\frac{2 J+1}{2 J} \operatorname{coth}\left(\frac{2 J+1}{2 J} x\right)-\frac{1}{2 J} \operatorname{coth}\left(\frac{x}{2 J}\right)$ with $x=\frac{J g \mu_{B}}{k_{B}}\left(\frac{\mu_{0} H+H_{e x c h}}{T}\right)$

with $J=$ spin momentum, $g=$ gyromagnetic factor, $\mu_{B}=$ Bohr magneton, $k_{B}=$ Boltzmann constant. By applying the reciprocal function of $f$ on the first member of Eq. (11), we can obtain:

$\frac{\mu_{0} H}{T}=f^{-1}(M)-\frac{H_{e x c h}}{T}=f^{-1}(M)-\frac{\lambda M}{T}$.

Using Fig 2b, we plotted in Fig $\mathbf{6 a}$ the variation of $\mu_{0} H / T$ vs. $1 / T$ at constant $M$ step (5 $\left.\mathrm{Am}^{2} \times \mathrm{kg}^{-1}\right)$. It's clear that the obtained iso-magnetization curves have a linear trend. Linear adjustments are then made on the linear parts of the iso-magnetization curves (red solid lines) giving the $H_{\text {exch }}$ values. In Fig. 6b we present the $H_{\text {exch }} v s M$ curve which has been adjusted using the following relation $[\mathbf{3 8}, \mathbf{3 9}]$ :

$H_{\text {exch }}=\lambda_{1} M+\lambda_{3} M^{3}$ 
The adjustment shows negligible value of $\lambda_{3}$ parameter $\left(\lambda_{3}=-0.0001\left(\mathrm{~T} \times \mathrm{Am}^{-2} \times \mathrm{kg}\right)^{3}\right)$, so the $H_{\text {exch }}$ expression can be approximated as $H_{\text {exch }}=\lambda M$, with $\lambda=\lambda_{1}=1.098 \mathrm{~T} \times$ $\mathrm{Am}^{-2} \times \mathrm{kg}$

The next step of this theory is to construct the $M v s\left(\frac{\mu_{0} H+H_{\text {exch }}}{T}\right)$ curves which are shown in Fig. 7 (black symbols). As observed, all these curves overlap in a single curve which has been adjusted using the Brillouin function as illustrated in Eq. (11). This adjustment represented by red line in Fig. 7 allows finding the values of $J, g$ and $M_{0}$ respectively as 2.03, 2.04 and 65 $\mathrm{Am}^{2} \times \mathrm{kg}^{-1}$. These values can be compared with the theoretical ones. In this case, the theoretical values of $J$ and $g$ are estimated by respecting the Hund rules [40]. As the orbital moment $(L)$ is blocked for the transition metal ions [40], only the contributions of $\mathrm{Mn}^{3+}$ and $\mathrm{Mn}^{4+}$ are considered for $\mathrm{La}_{0.7}^{3+} \mathrm{Ba}_{0.15}^{2+} \mathrm{Ag}_{0.15}^{2+} \mathrm{Mn}_{0.55}^{3+} \mathrm{Mn}_{0.45}^{4+} \mathrm{O}_{3}^{2-}$ sample, giving $\mathrm{J}=g=2$. It is clear that the experimental values of $J$ and $g$ match well with the theoretical ones. Thereafter, the adjusted values of $M_{0}, J$ and $g$ were injected into Eq. (11) in order to generate the theoretical $M\left(\mu_{0} H, T\right)$ isotherms represented by solid red lines in Fig. 8a which correlate well with the experimental isotherms indicated by black symbols. This confirms the utility of the mean field approach in the present study. On another side, according to the Bean-Rodbell model, the reduced magnetization $(\sigma)$ is expressed as a function of the Brillouin function as $[41,42]:$

$\sigma(Y)=B_{J}(Y)$

With

$Y=\frac{1}{T}\left[3 T_{0}\left(\frac{J}{J+1}\right) \sigma+\frac{g J \mu_{B}}{k_{B}} \mu_{0} H+\frac{9}{5} \frac{(2 J+1)^{4}-1}{[2(J+1)]^{4}} T_{0} \eta \sigma^{3}\right]$

where $T_{0}$ is the transition temperature, and $\eta$ is a parameter which can also checks the phasetransition order. Indeed, if $\eta<1$ a second order transition takes place; however a first order transition appears when $\eta>1$. Then, to model $M v s T$ under different magnetic field by the 
Bean-Rodbell model, we replace $x$ in Eq. (11), by $Y$ in Eq. (16). A simulation of the experimental $M(T)$ curves is established for $\eta=0.07$ and $T_{0}=255 \mathrm{~K}$ (see Fig. 8b). Seeing that $\eta<1$, the present sample presents a FM-PM phase transition of second-order type. The simulation of the curves of $-\Delta S_{M}(T)$ is achieved using the following relation:

$$
-\Delta S_{M}(T)_{H_{1} \rightarrow H_{2}}=\int_{\left.M\right|_{H_{1}}}^{\left.M\right|_{H_{2}}}\left(f^{-1}(M)-\left(\frac{\partial \lambda(T)}{\partial T}\right)_{M} M\right) d M
$$

Fig. 9 presents a comparison between the simulated $-\Delta S_{M}(T)$ curves (red lines) obtained using the mean field theory combined with the Bean-Rodbell model, and the experimental ones deduced from the Maxwell relation (black symbols). This simulation of the magnetic entropy variation shows well correlation between the simulated curves and the experimental ones. These results are in good agreement with those presented in previous works $[\mathbf{2 8 ,} \mathbf{3 1}, \mathbf{3 8}$, 39], where the mean field theory combined with the Bean-Rodbell model was used to estimate the magnetic entropy change from the data on the temperature and field dependences of the magnetization.

\section{Conclusion}

In this work the $\mathrm{La}_{0.7} \mathrm{Ba}_{0.15} \mathrm{Ag}_{0.15} \mathrm{MnO}_{3}$ manganite sample was prepared by sol-gel route. XRD analysis shows that the compound is good crystallized and its majority phase is a perovskite with rhombohedral $R \overline{3} c$ structure. The $M(T)$ measurement shows a second order FM-PM phase transition at $T_{C}=255 \mathrm{~K}$. From an application perspective, the sample can be used in the MR technology. An analysis of the spontaneous magnetization, $M_{\text {spont }}(T)$, was also carried out using the $\left(-\Delta S_{M} v s M^{2}\right)$ and $\left(\mu_{0} H / M v s M^{2}\right)$ data. The molecular mean-field, Bean Rodbell and Landau theories, were developed to model the magnetic entropy change for the sample. The theoretical results show good agreement with the experimental ones.

\section{Acknowledgments}

This project was supported by the Deanship of Scientific Research at Prince Sattam Bin Abdulaziz University under the research project No 2020/01/16565. 


\section{References}

[1] M.H. Phan, S.C. Yu, J. Magn. Magn. Mater. 308 (2007) 325.

[2] M. Hsini, S. Khadhraoui, N. Zaidi, Z.A. Alrowaili, J. Supercond. Nov. Magn. 31 (2018) 3717.

[3] S. Khadhraoui, M. Baazaoui, M. Hsini, M. Oumezzine, J. Supercond. Nov. Magn. 32 (2019) 291.

[4] V. Franco, A. Conde, E.J.M. Romero, J.S. Blazquez, J. Phys. Condens. Matter 20 (2008) 285207.

[5] S. Hcini, M. Boudard, S. Zemni, M. Oumezzine, Ceram. Int. 41 (2015) 2042.

[6] E. Oumezzine, M. Oumezzine, E.K. Hlil, J. Alloys Compd. 682 (2016) 366.

[7] S. Kallel, N. Kallel, O. Pe na, M. Oumezzine, Mater. Lett. 64 (2010) 1045.

[8] H. Yang, Q. Wu, N. Yu, Y. Yu, M. Pan, P. Zhang, H. Ge, J. Solid State Chem. 282 (2020) 121072.

[9] A.O. Ayaş, S.K. Çetin, M. Akyol, G. Akça, A. Ekicibil, J. Mol. Struct. 1200 (2020) 127120.

[10] A.D. Souza, M.S. Murari, M.D. Daivajna, Physica B Condens Matter. 580 (2020) 411909.

[11] E. Oumezzine, S. Hcini, E.K. Hlil, E. Dhahri, M. Oumezzine, J. Alloys Compd. 615 (2014) 553.

[12] S. Hcini, M. Boudard, S. Zemni, M. Oumezzine, Ceram. Int. 40 (2014) 16041.

[13] M. Baazaoui, M. Boudard, S. Zemni, Mater. Lett. 65 (2011) 2093.

[14] D.N.H. Nam, N.V. Dai, L.V. Hong, N.X. Phuc, S.C. Yu, M. Tachibana, E. TakayamaMuromachi, J. Appl. Phys. 103 (2008) 043905.

[15] S. Mahjoub, M. Baazaoui, E.K. Hlil, M. Oumezzine, Ceram. Int. 41 (2015) 12407.

[16] C.P. Reshmi, S.S. Pillai, K.G. Suresh, M.R. Varma, Solid State Sci. 19 (2013) 130.

[17] Y. Sun, W. Tong, Y.H. Zhang, J. Magn. Magn. Mater. 232 (2001) 205.

[18] T. Tang, K.M. Gu, Q.Q. Cao, D.H. Wang, S.Y. Wang, S.Y. Zhang, Y.W. Du, J. Magn. Magn. Mater. 222 (2000) 110.

[19] N.T. Hien, N.P. Thuy, Physica B Condens Matter. 319 (2002) 168.

[20] A.G. Gamzatov, A.S. Mankevich, Bull. Lebedev Phys. Inst. 36 (2009) 367.

[21] A.O. Ayaş, M. Akyol, A. Ekicibil, Philos. Mag. 96 (2016) 922.

[22] C.B. Larsena, S. Samothrakitis, A.D. Fortes, A.O. Ayaş, M. Akyol, A. Ekicibil, M. Laver, J. Magn. Magn. Mater. 498 (2020) 166192.

[23] R.D. Shannon, Acta Cryst. A 32 (1976) 751. 
[24] S. Hcini, S. Zemni, A. Triki, H. Rahmouni, M. Boudard, J. Alloys Compd. 509 (2011) 1394.

[25] A. Arrott, Phys. Rev. 108 (1957) 1394.

[26] S.K. Banerjee, Phys. Lett. 12 (1964) 16.

[27] V.K. Pecharsky Jr., K.A. Gschneidner, J. Magn. Magn. Mater. 167 (1997) L179.

[28] S. Khadhraoui, N. Zaidi, M. Hsini, Z.A. Alrowaili, J. Supercond. Nov. Magn. 32 (2019) 1285 .

[29] G.J. Liu, J.R. Sun, J. Lin, Y.W. Xie, T.Y. Zhao, H.W. Zhang, B.G. Shen, Appl. Phys. Lett. 88 (2006) 212505.

[30] H.E. Stanley, Introduction to Phase Transitions and Critical Phenomena, Oxford University Press, London, 1971.

[31] M. Hsini, S. Hcini, S. Zemni, J. Supercond. Nov. Magn. 31 (2018) 81.

[32] V.S. Amaral, J.S. Amaral, J. Magn. Magn. Mater. 272-276 (2004) 2104.

[33] S. Das, T.K. Dey, J. Phys. Condens. Matter. 18 (2006) 7629.

[34] S. Das, T.K. Dey, J. Alloys Comp. 440 (2007) 30.

[35] S. Das, T.K. Dey, J. Phys D, Appl Phys 40 (2007) 1855.

[36] S. Das, T.K. Dey, Mat. Chem. Phys. 108 (2008) 220.

[37] L. Jia, J. Sun, H. Zhang, F. Hu, C. Dong, B. Shen, J. Phys. Condens. Matter. 18 (2006) 9999.

[38] S. Yahyaoui, M. Khalfaoui, S. Kallel, N. Kallel, J.S. Amaral, A. Ben Lamine, J. Alloys Compd. 685 (2016) 633.

[39] S. Yahyaoui, M. Khalfaoui, S. Kallel, N. Kallel, J.S. Amaral, A. Ben, Lamine, J. Magn. Magn. Mater. 393 (2015) 105.

[40] C. Kittel, Introduction to Solid State Physics, 7th edn. (Wiley, New York, 1996).

[41] A.M. Tishin, Y.I. Spichkin, The Magnetocaloric Effect and its Applications, IOP Publishing, London, 2003.

[42] R. Zach , M. Guillot, J. Tobola, J. Appl. Phys. 83 (1998) 7237. 


\section{Table legends}

Table 1: Rietveld refinement of the structural parameters for $\mathrm{La}_{0.7} \mathrm{Ba}_{0.15} \mathrm{Ag}_{0.15} \mathrm{MnO}_{3}$ manganite. The numbers in parentheses are estimated standard deviations to the last significant digit.

\begin{tabular}{|c|c|c|c|c|}
\hline \multicolumn{4}{|l|}{ Sample } & $\mathrm{La}_{0.7} \mathrm{Ba}_{0.15} \mathrm{Ag}_{0.15} \mathrm{MnO}_{3}$ \\
\hline \multirow{3}{*}{$\begin{array}{l}\text { Cell } \\
\text { parameters }\end{array}$} & \multicolumn{3}{|l|}{$a(\AA)$} & $5.5216(1)$ \\
\hline & \multicolumn{3}{|l|}{$c(\AA)$} & $13.4259(3)$ \\
\hline & \multicolumn{3}{|l|}{$V\left(\AA^{3}\right)$} & $354.487(1)$ \\
\hline \multirow[t]{12}{*}{ Atoms } & \multirow[t]{4}{*}{ La/Ba/Ag } & Wyckoff Positions & & $6 a$ \\
\hline & & Site Symmetry & & 32 \\
\hline & & Atomic Positions & $(x, y, z)$ & $(0,0,1 / 4)$ \\
\hline & & Isotropic Debye-Waller factor & $B_{\text {iso }}\left(\AA^{2}\right)$ & $1.18(3)$ \\
\hline & \multirow[t]{4}{*}{$M n$} & Wyckoff Positions & & $6 b$ \\
\hline & & Site Symmetry & & -3 \\
\hline & & Atomic Positions & $(x, y, z)$ & $(0,0,0)$ \\
\hline & & Isotropic Debye-Waller factor & $B_{i s o}\left(\AA^{2}\right)$ & $0.20(0)$ \\
\hline & \multirow[t]{4}{*}{$O$} & Wyckoff Positions & & $18 \mathrm{e}$ \\
\hline & & Site Symmetry & & 2 \\
\hline & & Atomic Positions & $(x, y, z)$ & $(0.5201(2), 0,1 / 4)$ \\
\hline & & Isotropic Debye-Waller factor & $B_{\text {iso }}\left(\AA^{2}\right)$ & $2.04(1)$ \\
\hline \multirow{3}{*}{$\begin{array}{l}\text { Structural } \\
\text { parameters }\end{array}$} & & Bond length & $d_{M n-O}(\AA)$ & $1.9505(6)$ \\
\hline & & Bond angle & $\theta_{M n-O-M n}\left({ }^{\circ}\right)$ & $173.51(3)$ \\
\hline & & Average grains size & $t(n m)$ & 46 \\
\hline \multirow{4}{*}{$\begin{array}{l}\text { Agreement } \\
\text { factors }\end{array}$} & \multicolumn{2}{|c|}{ Profile factor } & $R_{p}(\%)$ & 1.43 \\
\hline & \multicolumn{2}{|c|}{ Weighted profile factor } & $R_{w p}(\%)$ & 2.01 \\
\hline & \multicolumn{2}{|c|}{ Structure factor } & $R_{F}(\%)$ & 3.15 \\
\hline & \multicolumn{2}{|c|}{ Goodness of fit } & $\chi^{2}(\%)$ & 2.53 \\
\hline
\end{tabular}


Table 2: Magnetocaloric parameters at $\mu_{0} H=5 \mathrm{~T}$ for $\mathrm{La}_{0.7} \mathrm{Ba}_{0.15} \mathrm{Ag}_{0.15} \mathrm{MnO}_{3}$ manganite (present work) compared to several materials considered for magnetic refrigeration technology.

\begin{tabular}{llllll}
\hline Samples & $\boldsymbol{T}_{\boldsymbol{C}}(\mathbf{K})$ & $\Delta \boldsymbol{\mu}_{\boldsymbol{0}} \boldsymbol{H}(\mathbf{T})$ & $\left|\Delta \boldsymbol{S}_{\boldsymbol{M}}^{\mathbf{m a x}}\right|\left(\mathbf{J} \times \mathbf{K g}^{-\mathbf{1}} \times \mathbf{K}^{-\mathbf{1}}\right)$ & $\mathbf{R C P}\left(\mathbf{J} \times \mathbf{K g}^{-\mathbf{1}}\right)$ & Ref. \\
\hline $\mathrm{La}_{0.7} \mathrm{Ba}_{0.15} \mathrm{Ag}_{0.15} \mathrm{MnO}_{3}$ & 255 & 5 & 3.48 & 225 & Present work \\
$\mathrm{Gd}$ & 293 & 5 & 9.5 & 410 & {$[21]$} \\
$\mathrm{Gd}_{5} \mathrm{Si}_{2} \mathrm{Ge}_{2}$ & 275 & 5 & 18.5 & 535 & {$[21]$} \\
$\mathrm{La}_{0.6} \mathrm{Pr}_{0.1} \mathrm{Ba}_{0.3} \mathrm{MnO}_{3}$ & 215 & 5 & 1.97 & 230 & {$[5]$} \\
$\mathrm{La}_{0.6} \mathrm{Pr}_{0.1} \mathrm{Ba}_{0.3} \mathrm{Mn}_{0.9} \mathrm{Ni}_{0.1} \mathrm{O}_{3}$ & 162 & 5 & 1.31 & 123 & {$[5]$} \\
$\mathrm{Nd}_{0.67} \mathrm{Ba}_{0.33} \mathrm{MnO}_{3}$ & 145 & 5 & 3.91 & 265 & {$[6]$} \\
$\mathrm{Nd}_{0.67} \mathrm{Ba}_{0.33} \mathrm{Mn}_{0.98} \mathrm{Fe}_{0.02} \mathrm{O}_{3}$ & 134 & 5 & 2.97 & 242 & {$[6]$} \\
$\mathrm{La}_{0.67} \mathrm{Ba}_{0.33} \mathrm{Mn}_{0.95} \mathrm{Fe}_{0.05} \mathrm{O}_{3}$ & 271 & 5 & 2.54 & 246 & {$[7]$} \\
$\mathrm{Pr}_{0.67} \mathrm{Ba}_{0.33} \mathrm{Mn}_{0.95} \mathrm{Fe}_{0.05} \mathrm{O}_{3}$ & 128 & 5 & 3.09 & 287 & {$[7]$} \\
$\mathrm{La}_{0.7} \mathrm{Sr}_{0.3} \mathrm{Mn}_{0.95} \mathrm{Al}_{0.05} \mathrm{O}_{3}$ & 332 & 5 & 4.4 & 192 & {$[8]$} \\
$\mathrm{Pr}_{0.6} \mathrm{Ca}_{0.1} \mathrm{Sr}_{0.3} \mathrm{Mn}_{0.975} \mathrm{Fe}_{0.025} \mathrm{O}_{3}$ & 235 & 5 & 3.53 & 132 & {$[9]$} \\
$\mathrm{La}_{0.67} \mathrm{Sr}_{0.33} \mathrm{Mn}_{0.9} \mathrm{Ni}_{0.1} \mathrm{O}_{3}$ & 290 & 5 & 3 & 200 & {$[10]$} \\
$\mathrm{La}_{0.67} \mathrm{Sr}_{0.33} \mathrm{Mn}_{0.9} \mathrm{Co}_{0.1} \mathrm{O}_{3}$ & 328 & 5 & 5.00 & {$[11]$} \\
\hline
\end{tabular}


Figure captions
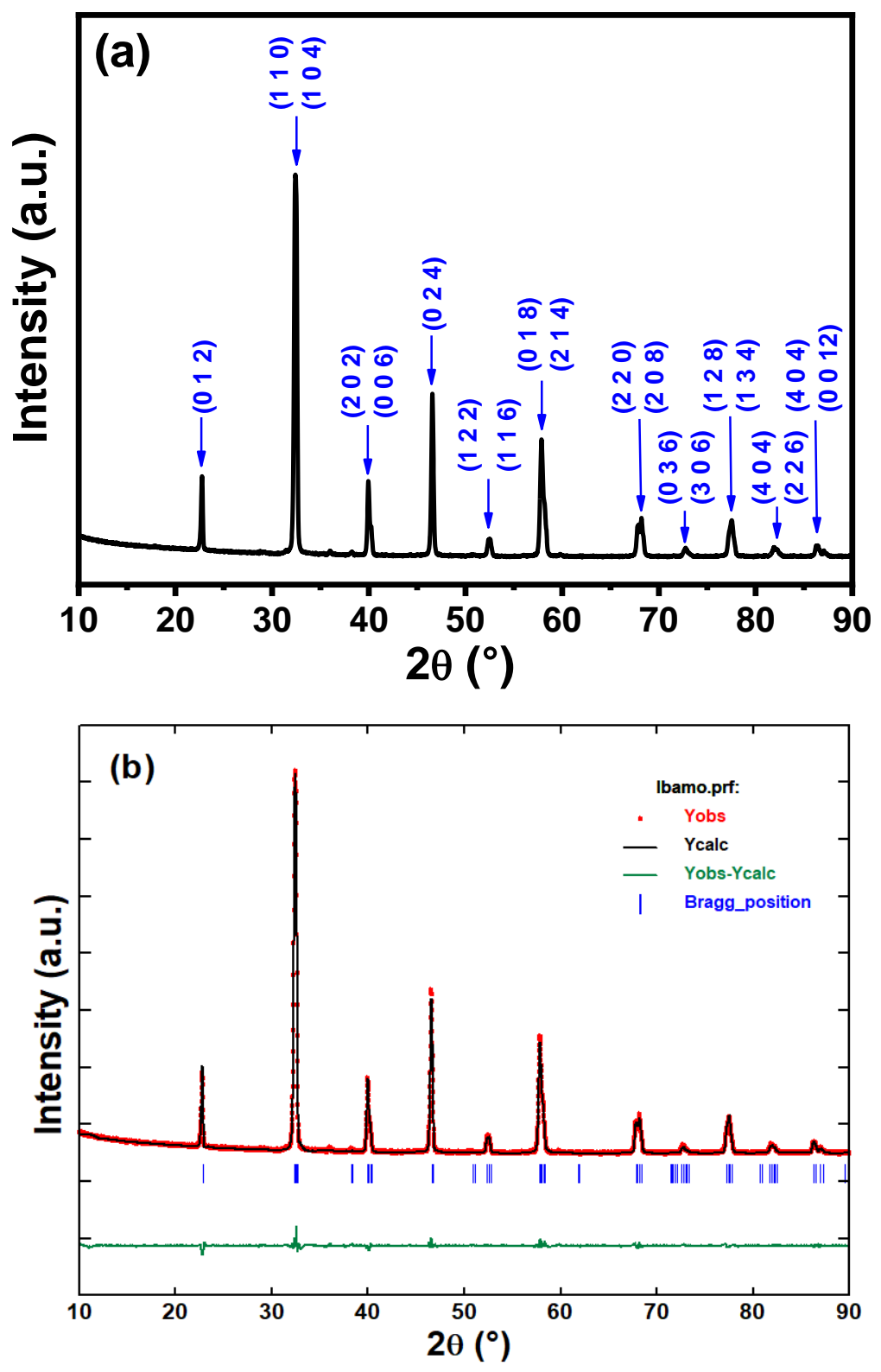

Fig. 1: (a) X-ray diffraction pattern for $\mathrm{La}_{0.7} \mathrm{Ba}_{0.15} \mathrm{Ag}_{0.15} \mathrm{MnO}_{3}$ manganite. All peaks are indexed in the hexagonal setting of the rhombohedral $R \overline{3} c$ symmetry. (b) Rietveld analysis of XRD pattern. The bottom line (green) represents the difference between the XRD data (red) and calculated fit (black), and the blue lines are Bragg positions. 

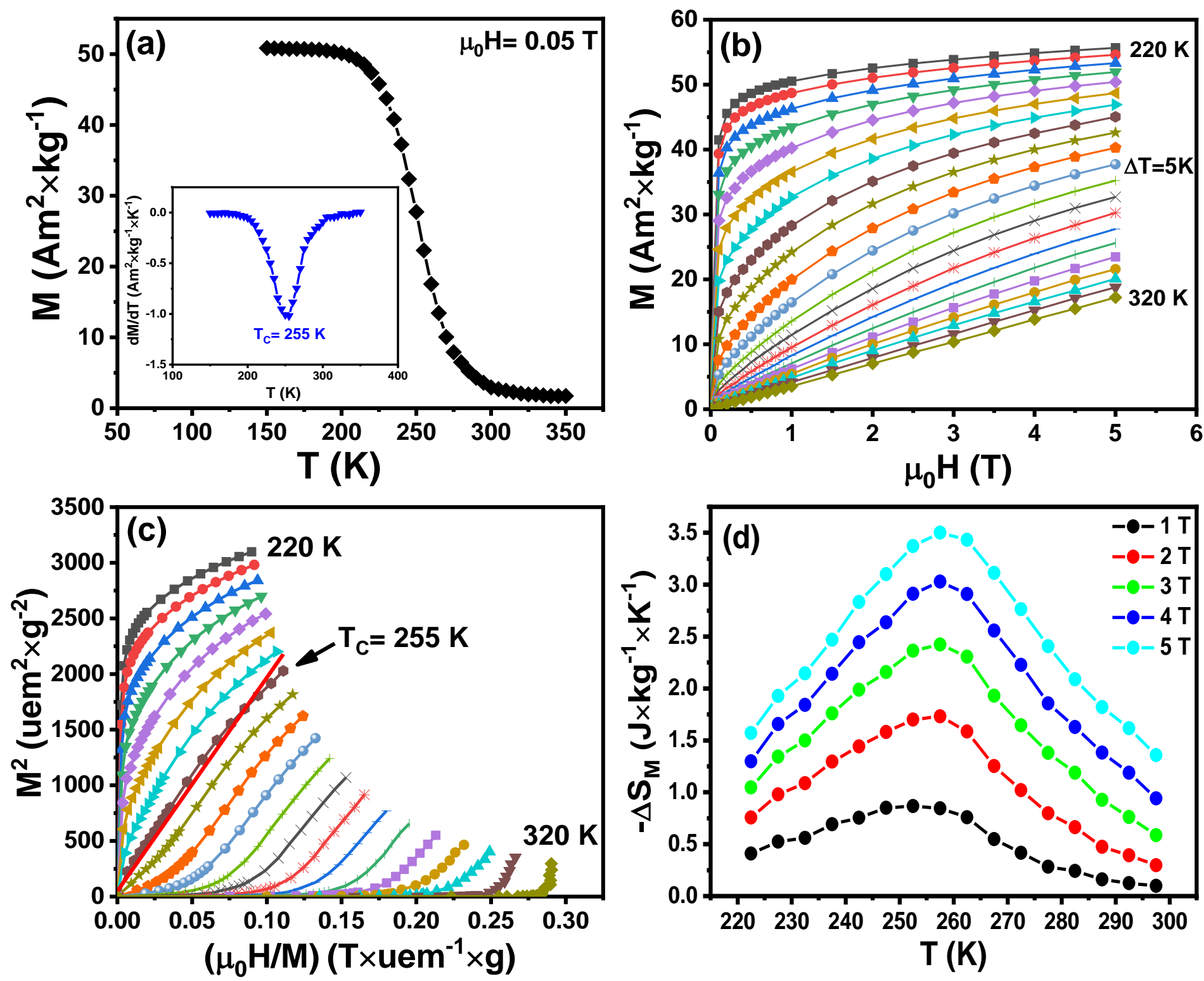

Fig. 2: (a) Temperature dependence of magnetization and $d M / d T$ vs $T$ curve at $\mu_{0} H=0.05 \mathrm{~T}$. (b) Magnetization isotherms. (c) Arrott plots around $T_{C}$. (d) Magnetic entropy change $v s T$ at various applied magnetic fields. 

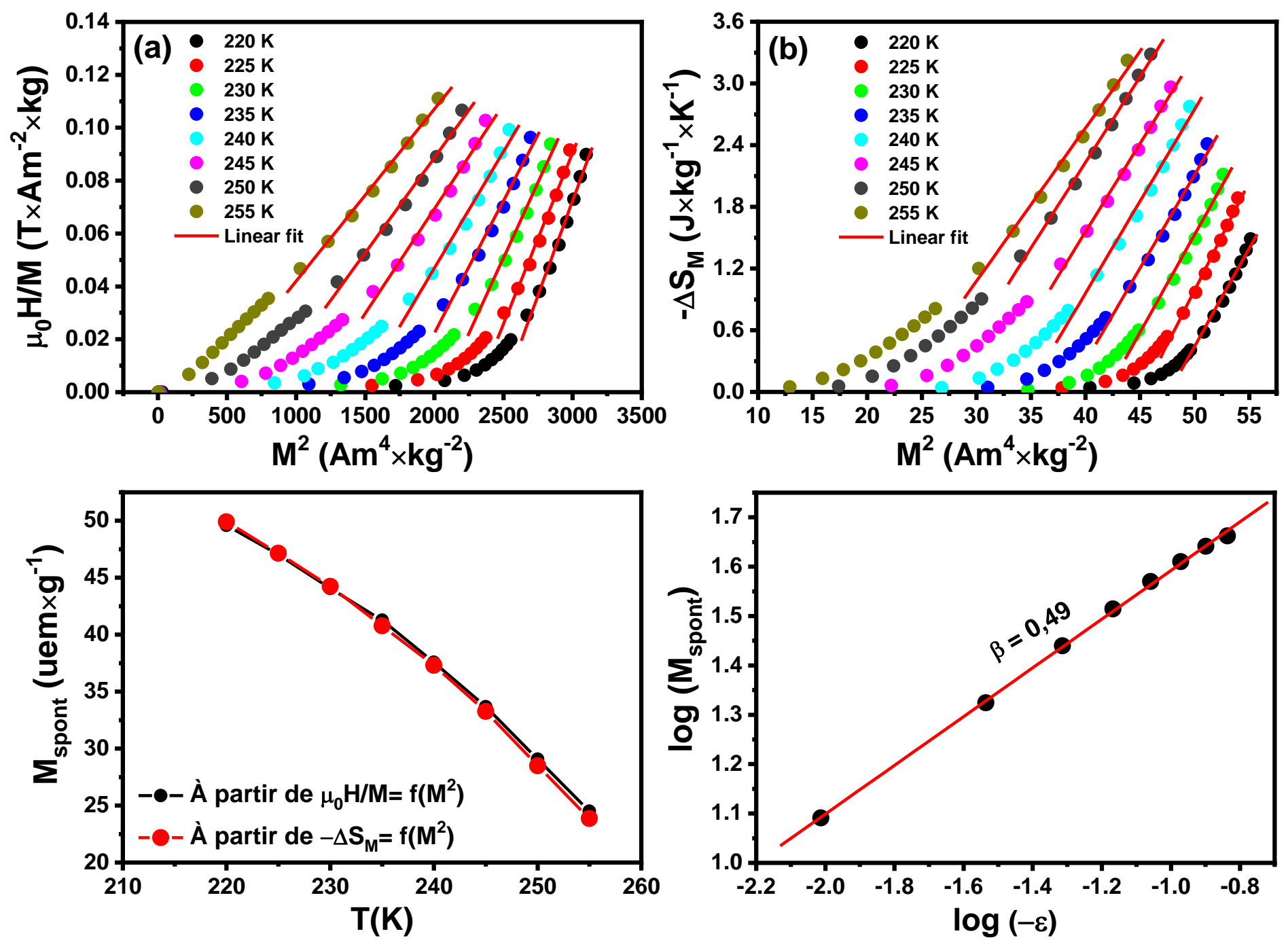

Fig. 3: (a) Linear fits (red lines) for $T<T_{C}$ of Arrott plots $\left(\frac{\mu_{0} \mathrm{H}}{\mathrm{M}} v s \mathrm{M}^{2}\right)$. (b) Linear fits (red lines) of $-\Delta S_{M}$ vs $M^{2}$ curves. (c) $M_{\text {spont }}$ vs $T$ deduced from $-\Delta S_{M}$ vs $M^{2}$ curves (black symbols) and from the Arrott plots $\left(\frac{\mu_{0} \mathrm{H}}{\mathrm{M}} v s \mathrm{M}^{2}\right)$ (red symbols). (d) Linear fit of $\log M_{\text {spont }} v s \log (-\varepsilon)$ deduced from $-\Delta S_{M}$ vs $M^{2}$ curves. 

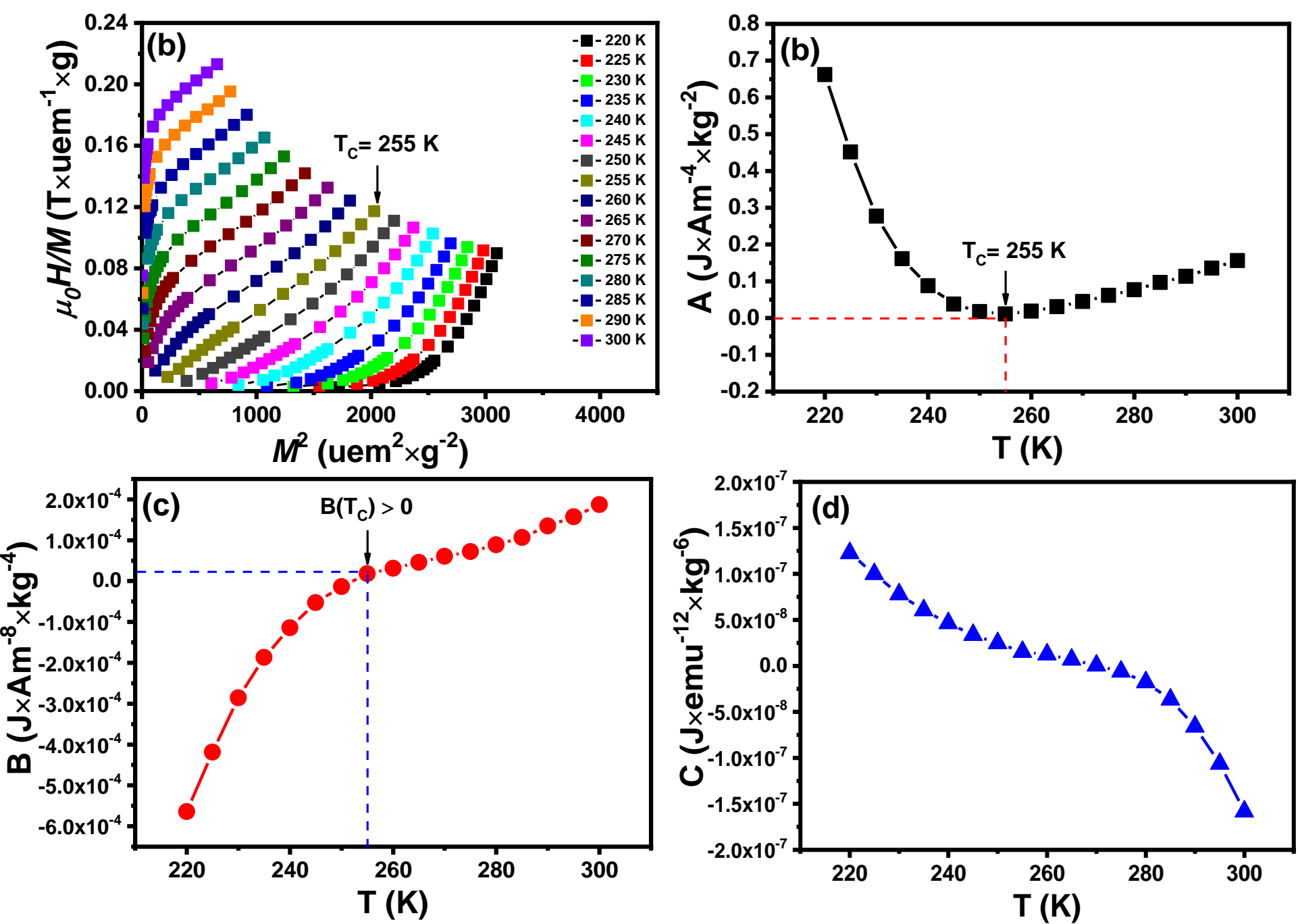

Fig. 4: (a) Quadratic fit (red lines) of $\left(\frac{\mu_{0} \mathrm{H}}{\mathrm{M}} v s \mathrm{M}^{2}\right)$. (b) Variation of Landau parameter $A(T)$. (c) Variation of Landau parameter $B(T)$. (d) Variation of Landau parameter $C(T)$. 


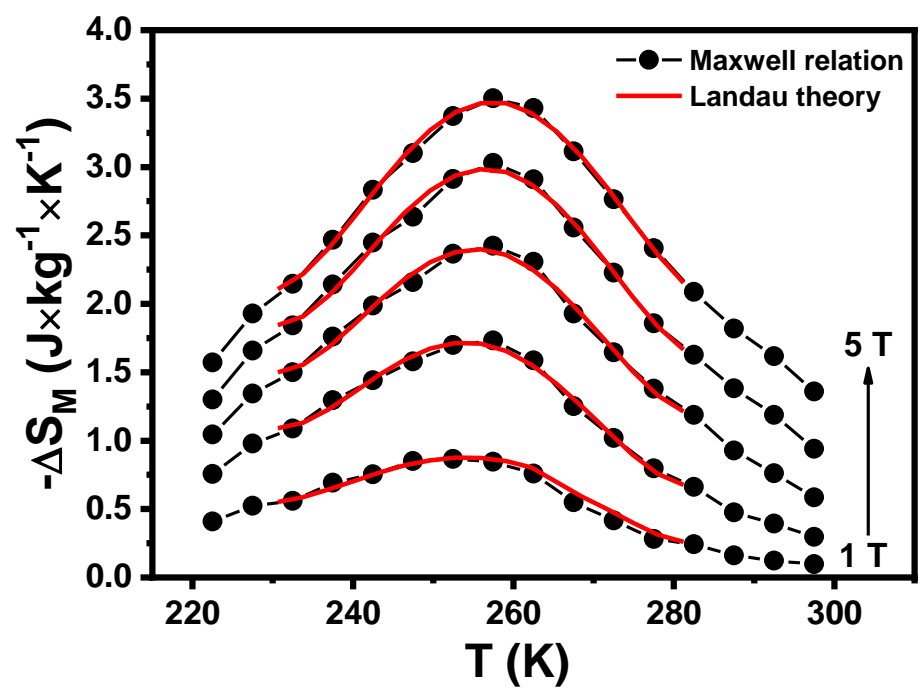

Fig. 5: Comparison between $-\Delta S_{M} v s T$ under various applied magnetic fields estimated from Maxwell relation (black symbols) and Landau theory (red lines). 

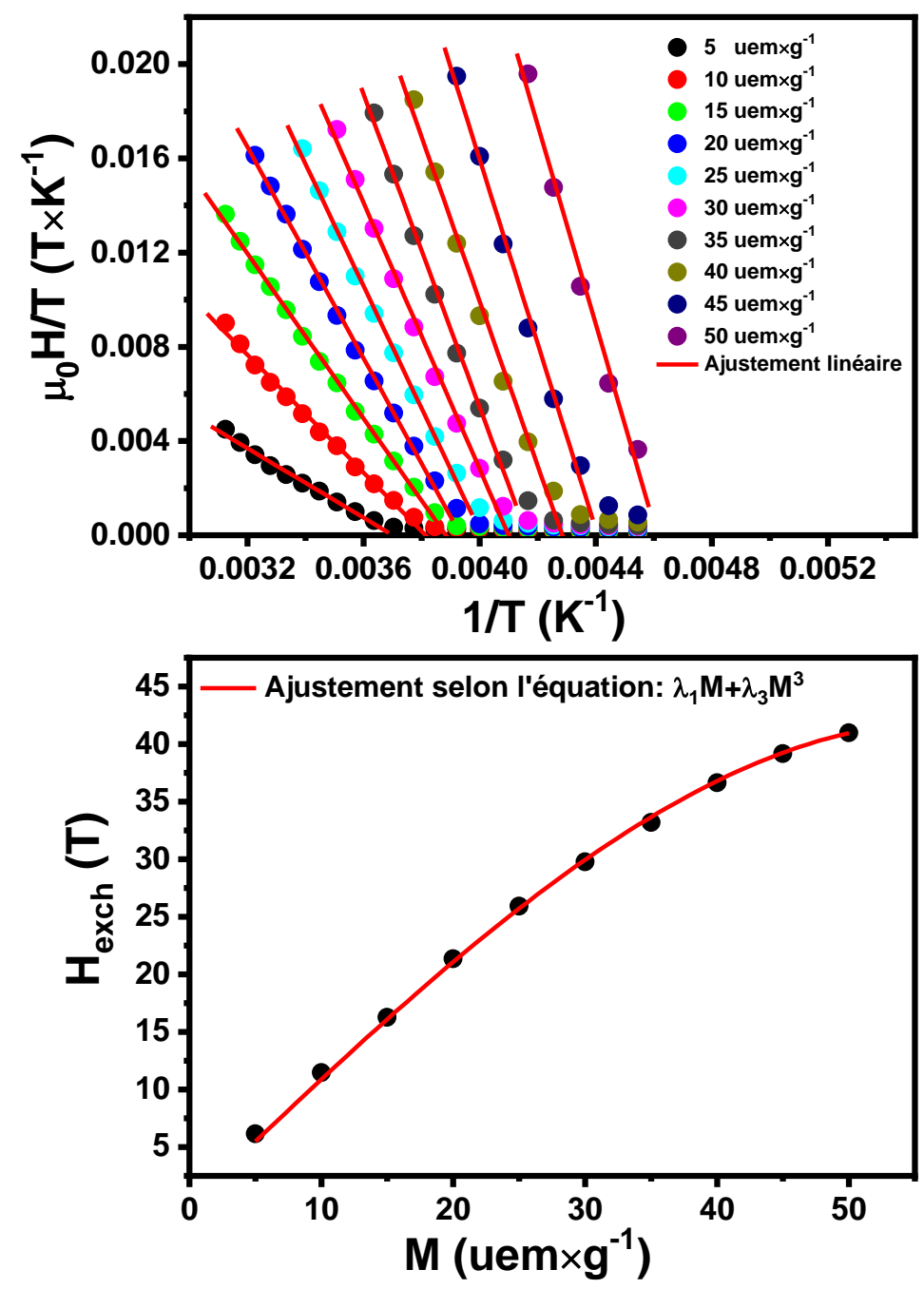

Fig. 6: (a) $\frac{\mu_{0} H}{T}$ vs $\frac{1}{T}$ curves under constant magnetization $\left(M=5 \mathrm{Am}^{2} \times \mathrm{kg}^{-1}\right)$. (b) $H_{\text {exch }} v s$ $M$ fitted by $\lambda_{1} M+\lambda_{3} M^{3}$ function. 


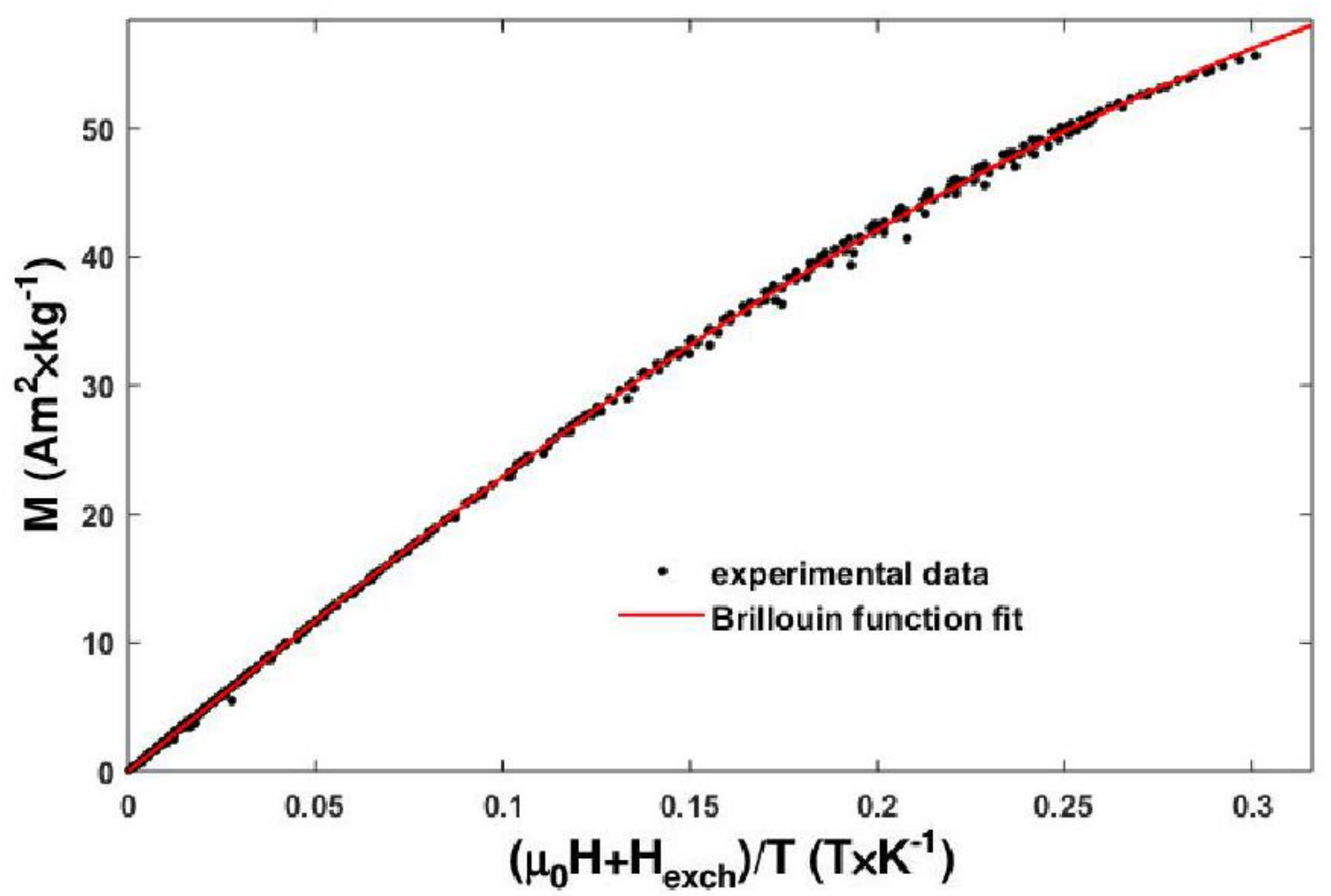

Fig. 7: $M v s \frac{\mu_{0} H+H_{\text {exch }}}{T}$ scaling plots fitted using Brillouin function. 

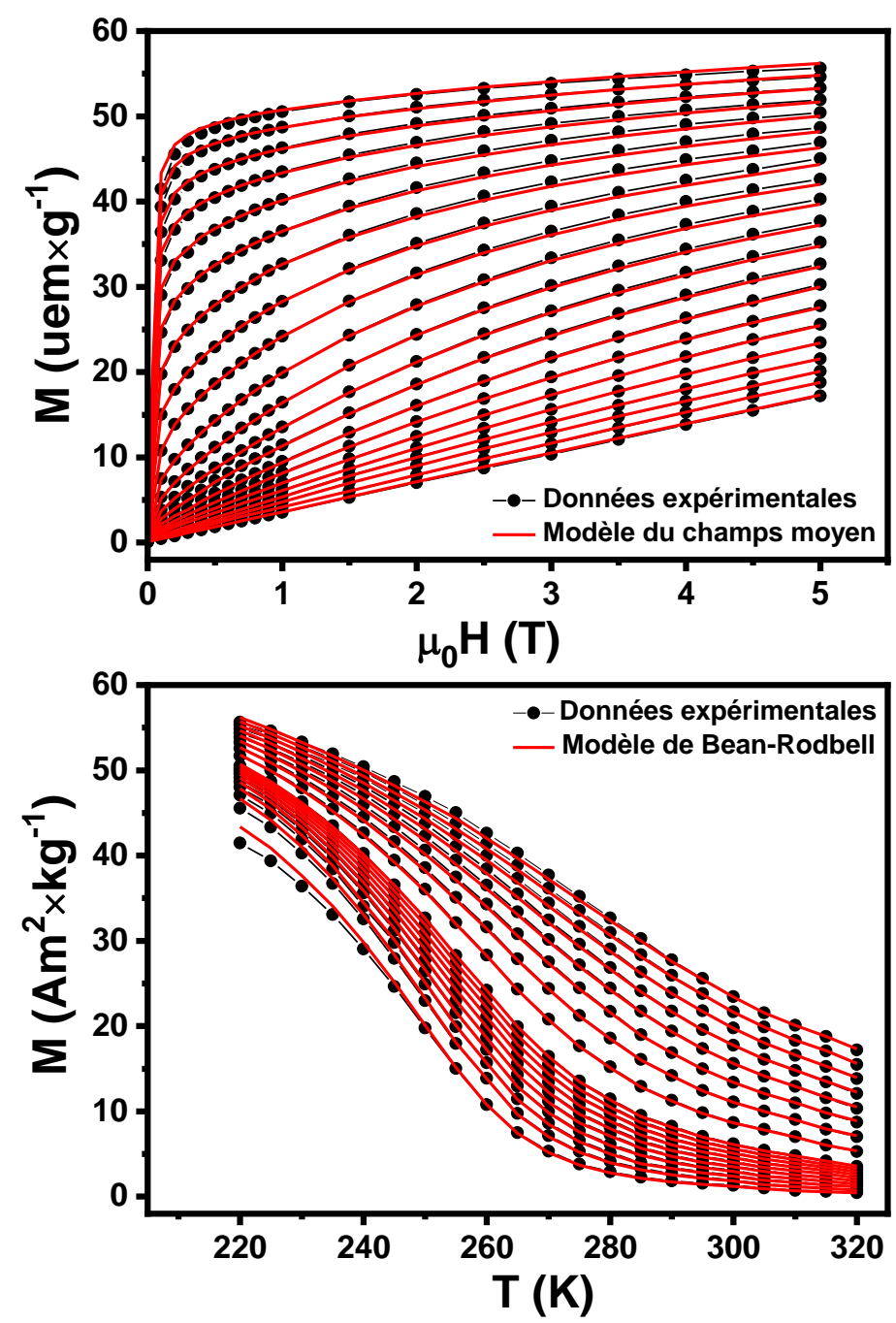

Fig. 8: (a) $M$ vs $H$ curves (black symbols) with the interpolation using the mean-field method (red lines). (b) $M$ vs $T$ curves (black symbols) with the interpolation using the Bean- Rodbell model (red lines). 


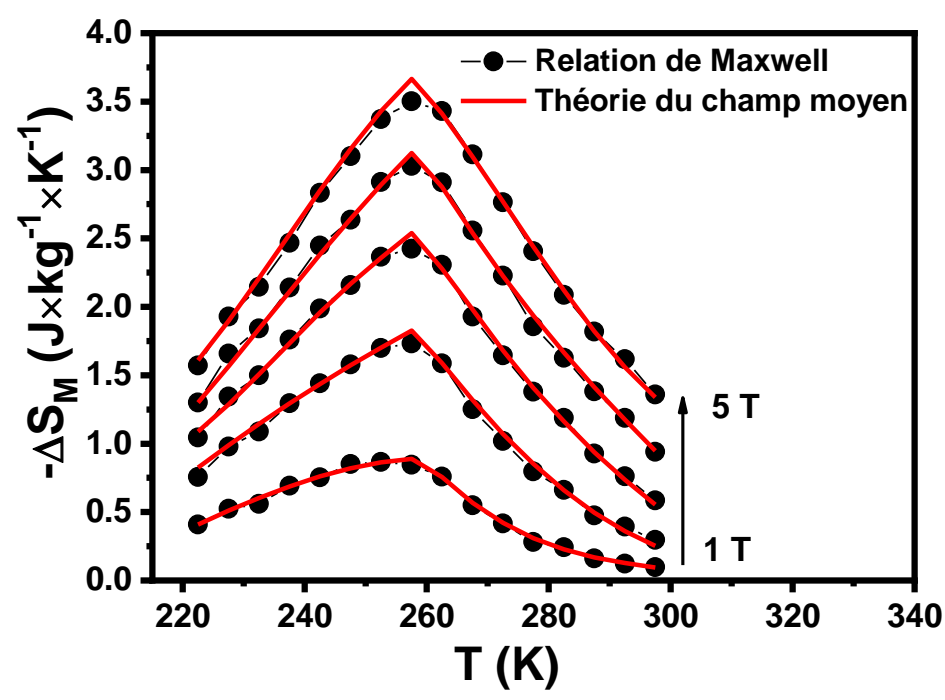

Fig. 9: Comparison between $-\Delta S_{M} v s T$ under various applied magnetic fields estimated from Maxwell relation (black symbols) and mean field model (red lines). 